\title{
Decision-making algorithm for ascending aortic aneurysm: Effectiveness in clinical application?
}

Ayman Saeyeldin, MD, ${ }^{\text {a,b }}$ Mohammad A. Zafar, MBBS, ${ }^{a}$ Yupeng Li, PhD, ${ }^{\mathrm{c}}$ Maryam Tanweer, MD, ${ }^{\mathrm{a}}$ Mohamed Abdelbaky, MD, ${ }^{\mathrm{a}}$ Anton Gryaznov, MD, PhD, ${ }^{\mathrm{a}, \mathrm{d}}$ Adam J. Brownstein, MD, ${ }^{\mathrm{a}}$ Camilo A. Velasquez, MD, ${ }^{a}$ Joelle Buntin, MSN, RN, RN-BC, ${ }^{a}$ Kabir Thombre, BA, ${ }^{a}$ Wei-Guo Ma, MD, PhD, ${ }^{\mathrm{a}, \mathrm{e}}$ Young Erben, MD, John A. Rizzo, PhD, ${ }^{\mathrm{g}}$ Bulat A. Ziganshin, MD, PhD, ${ }^{\mathrm{a}, \mathrm{h}}$ and John A. Elefteriades, MD, $\mathrm{PhD}(\text { hon })^{\mathrm{a}}$

\section{ABSTRACT}

Objective: The risk of rupture and dissection in ascending thoracic aortic aneurysms increases as the aortic diameter exceeds $5 \mathrm{~cm}$. This study evaluates the clinical effectiveness of a specific algorithm based on size and symptoms for preemptive surgery to prevent complications.

Methods: A total of 781 patients with nondissecting ascending thoracic aortic aneurysms who presented electively for evaluation to our institution from 2011 to 2017 were triaged to surgery $(\mathrm{n}=607,77 \%)$ or medical observation $(\mathrm{n}=181$, $24 \%$ ) based on a specific algorithm: surgery for large $(>5 \mathrm{~cm})$ or symptomatic aneurysms. A total of 309 of 781 patients did not undergo surgery. Of these, $128(16 \%)$ had been triaged to prompt repair but did not undergo surgery for a variety of reasons ("surgery noncompliant and overwhelming comorbidities" group). Another 181 patients (24\%) were triaged to medical management ("medical" group).

Results: In the "surgery noncompliant and overwhelming comorbidities" versus the "medical" group, mean aortic diameters were $5 \pm 0.5 \mathrm{~cm}$ versus $4.45 \pm 0.4 \mathrm{~cm}$ and aortic events (rupture/dissection) occurred in 17 patients $(13.3 \%)$ versus 3 patients $(1.7 \%)$, respectively $(P<.001)$. Later elective surgeries (representing late compliance in the "surgery noncompliant and overwhelming comorbidities group" or onset of growth or symptoms in the "medical" group) were conducted in 21 patients $(16.4 \%)$ versus 15 patients $(8.3 \%)(P=.04)$, respectively. Death ensued in 20 patients $(15.6 \%)$ versus 6 patients $(3.3 \%)$ $(P<.001)$, respectively. In the "surgery noncompliant and overwhelming comorbidities" group, 7 of 20 patients died of definite aortic causes compared with none in the "medical" group.

Conclusions: Patients with ascending thoracic aortic aneurysms who did not follow surgical recommendations experienced substantially worse outcomes compared with medically triaged candidates. The specific algorithm based on size and symptoms functioned effectively in the clinical setting, correctly identifying both at-risk and safe patients. ( $\mathrm{J}$ Thorac Cardiovasc Surg 2019;157:1733-45)

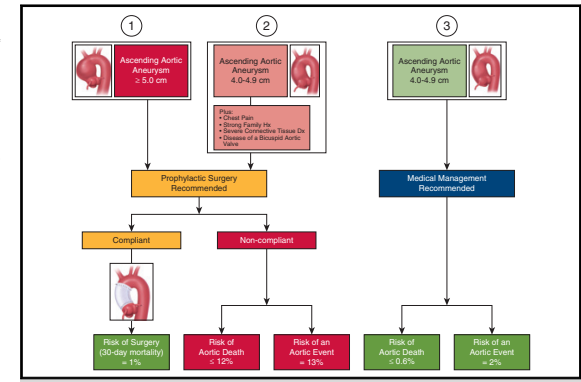

Schematic of the decision-making algorithm and main outcomes for each group of patients.

\section{Central Message}

A specific algorithm for triaging patients with ascending aortic aneurysms based on size and symptoms functioned effectively in the clinical setting, correctly identifying both at-risk and safe patients.

Perspective

Aortic diameter remains a powerful predictor of adverse aortic events and forms the basis of surgical intervention criteria that have been established for prophylactic repair of ascending aortic aneurysm. Chest pain is also an important indicator. This evaluation of decision making based on size and symptoms reveals accurate triage to preserve life and avoid unnecessary surgery.

See Commentaries on pages 1746 and 1748.

\footnotetext{
From the a Aortic Institute at Yale-New Haven Hospital, Yale University School of Medicine, New Haven, Conn; ' Department of Internal Medicine, Saint Mary's Hospital, Waterbury, Conn; ${ }^{c}$ Department of Political Sciences and Economics, Rowan University, Glassboro, NJ; ' Department of Surgery, Saint Mary's Hospital, Waterbury, Conn; ${ }^{\mathrm{e}}$ Department of Cardiovascular Surgery, Beijing Anzhen Hospital of Capital Medical University, Beijing, China; ${ }^{\mathrm{f}}$ Department of Vascular Surgery, Yale University School of Medicine, New Haven, Conn; ${ }^{g}$ Department of Economics and Department of Preventive Medicine, Stony Brook University, Stony Brook, NY; and ${ }^{\mathrm{h}}$ Department of Surgical Diseases \#2, Kazan State Medical University, Kazan, Russia.
}

Read at the 98th Annual Meeting of The American Association for Thoracic Surgery, San Diego, California, April 28-May 1, 2018.

Received for publication April 17, 2018; revisions received Aug 21, 2018; accepted for publication Sept 4, 2018; available ahead of print Dec 20, 2018

Address for reprints: John A. Elefteriades, MD, PhD (hon), Aortic Institute at YaleNew Haven, Yale University School of Medicine, 789 Howard Ave, Clinic Build ing - CB317, New Haven, CT 06519 (E-mail: john.elefteriades@yale.edu). $0022-5223 / \$ 36.00$

Copyright (C) 2018 by The American Association for Thoracic Surgery https://doi.org/10.1016/j.jtcvs.2018.09.124 


\section{Abbreviations and Acronyms}

$\mathrm{AD}=$ aortic dissection

AHI $=$ aortic height index

ASI $=$ aortic size index

ATAA $=$ ascending thoracic aortic aneurysm

Scanning this QR code will take you to the article title page to access supplementary information. To view the AATS Annual Meeting Webcast, see the URL next to the webcast thumbnail.

Ascending thoracic aortic aneurysms (ATAAs) are slowly progressive but life-threatening diseases because of the natural risk of complications if left unchecked. ATAAs can aptly be termed "silent killers," because aneurysms seldom produce symptoms until dreadful complications occur, namely, aortic dissection (AD), rupture, and death.

Several limitations can hinder the study of the natural history of unrepaired ATAAs, including the relative rarity of the condition, the impact of censoring data at the time of intervention (ie, selecting out patients before they die of their disease), and the difficulty in accurately ascertaining the causes of death in these patients (many of them are misclassified as "cardiac" causes). Reports of routine radiographic imaging of patients who had sudden cardiac death have shown that a significant number of these patients (a staggering $8.3 \%$ ) had type $\mathrm{A} \mathrm{AD}$ as the cause of death., ${ }^{2,3}$

In 1997, our group first reported on the natural history of the thoracic aorta, estimating growth rates and displaying diameter "hinge points" at which the risk of aortic rupture or dissection increased sharply. ${ }^{4}$ Our subsequent studies, based on a larger number of patients, permitted more robust calculations that validated these dangerous diameters and

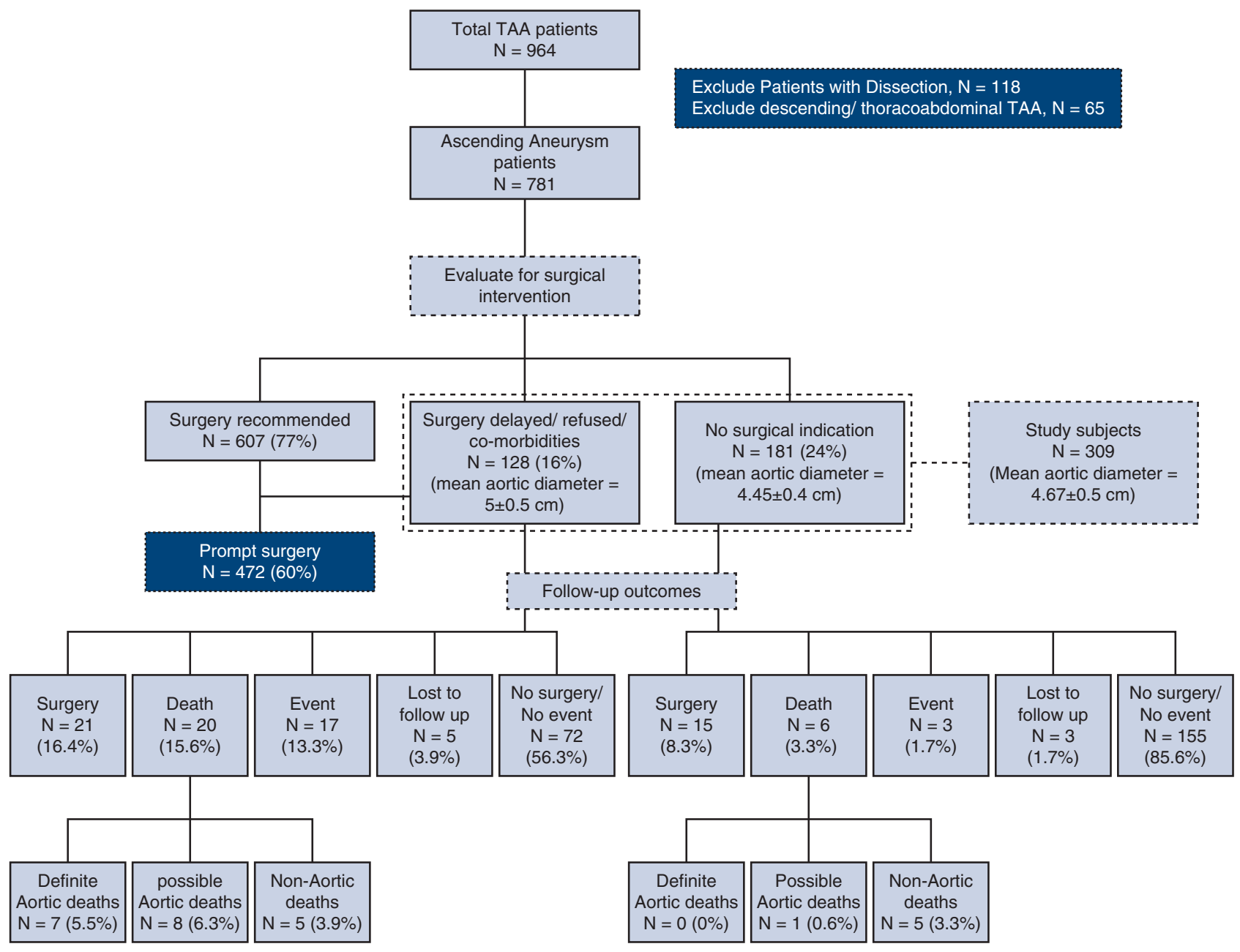

FIGURE 1. Flowchart for study patient triage and outcomes. TAA, Thoracic aortic aneurysm. 
TABLE 1. Patient characteristics

\begin{tabular}{|c|c|c|c|c|c|}
\hline Parameter* & $\begin{array}{c}\text { Surgery "noncompliant and } \\
\text { overwhelming comorbidities", } \\
\text { group }(n=128)\end{array}$ & Medical group $(n=181)$ & Chi-square & $P$ value & Total $(\mathbf{n}=\mathbf{3 0 9})$ \\
\hline Age (y) & $66.7 \pm 13.6$ & $67 \pm 14$ & - & - & $66.8 \pm 13.8$ \\
\hline \multicolumn{6}{|l|}{ Sex, n $(\%)$} \\
\hline Male & $89(69.5 \%)$ & $132(72.9 \%)$ & 0.274 & .6004 & $221(71.5 \%)$ \\
\hline Female & $39(30.5 \%)$ & $49(27.1 \%)$ & 0.274 & .6004 & $88(28.5 \%)$ \\
\hline Height $(\mathrm{cm})$ & $173.9 \pm 10.6$ & $175.4 \pm 11.4$ & - & - & $174.78 \pm 11.07$ \\
\hline Weight $(\mathrm{kg})$ & $87.5 \pm 22.9$ & $68.3 \pm 22.6$ & - & - & $86.77 \pm 22.67$ \\
\hline Body surface area $\left(\mathrm{m}^{2}\right)$ & $2.04 \pm 0.3$ & $2.03 \pm 0.3$ & - & - & $2.03 \pm 0.3$ \\
\hline Body mass index $\left(\mathrm{kg} / \mathrm{m}^{2}\right)$ & $28.8 \pm 6.12$ & $27.7 \pm 5$ & - & - & $28.12 \pm 5.53$ \\
\hline Previous cardiac surgery, $\mathrm{n}(\%)$ & $13(10.2 \%)$ & $14(7.7 \%)$ & 0.289 & .5906 & $27(8.7 \%)$ \\
\hline Coronary artery bypass grafting & $10(7.8 \%)$ & $7(3.9 \%)$ & 1.55 & .2132 & $17(5.5 \%)$ \\
\hline Aortic valve replacement & $4(3.1 \%)$ & $7(3.9 \%)$ & 0.001 & .9718 & $11(3.6 \%)$ \\
\hline Mitral valve replacement & $1(0.8 \%)$ & $1(0.6 \%)$ & 0.061 & .8049 & $2(0.7 \%)$ \\
\hline \multicolumn{6}{|l|}{ Imaging findings } \\
\hline \multicolumn{6}{|l|}{ Main lesion location, $\mathrm{n}(\%)$} \\
\hline Root & $27(21.1 \%)$ & $35(19.3 \%)$ & 0.056 & .8137 & $62(20 \%)$ \\
\hline Mid-ascending & $95(74.2 \%)$ & $144(79.6 \%)$ & 0.934 & .3338 & $239(77.4 \%)$ \\
\hline Arch & $6(4.7 \%)$ & $2(1.1 \%)$ & 2.527 & .1119 & $8(2.6 \%)$ \\
\hline Maximal diameter $(\mathrm{cm})$ & $5.0 \pm 0.5$ & $4.45 \pm 0.5$ & & & $4.67 \pm 0.5$ \\
\hline Aortic height index $(\mathrm{cm} / \mathrm{m})$ & $2.9 \pm 0.4$ & $2.53 \pm 0.21$ & - & - & $2.67 \pm 0.35$ \\
\hline Aortic size index $\left(\mathrm{cm} / \mathrm{m}^{2}\right)$ & $2.2 \pm 0.3$ & $2.5 \pm 0.5$ & - & - & $2.33 \pm 0.41$ \\
\hline \multicolumn{6}{|l|}{ Measurement modality, n (\%) } \\
\hline Computed tomography & $110(85.9 \%)$ & $140(77.4 \%)$ & 3.046 & .0809 & $250(80.9 \%)$ \\
\hline Magnetic resonance imaging & $6(4.7 \%)$ & $12(6.6 \%)$ & 0.222 & .6373 & $18(5.8 \%)$ \\
\hline Echo & $12(9.4 \%)$ & $29(16 \%)$ & 2.33 & .1269 & $41(12.3 \%)$ \\
\hline
\end{tabular}

*Continuous variables are presented as mean \pm standard deviation.

proposed indexing aortic diameter to anthropometric measures to account for the size differences in these patients. ${ }^{5-8}$ Current practice guidelines and recent analyses recommend preemptive surgical intervention at ascending

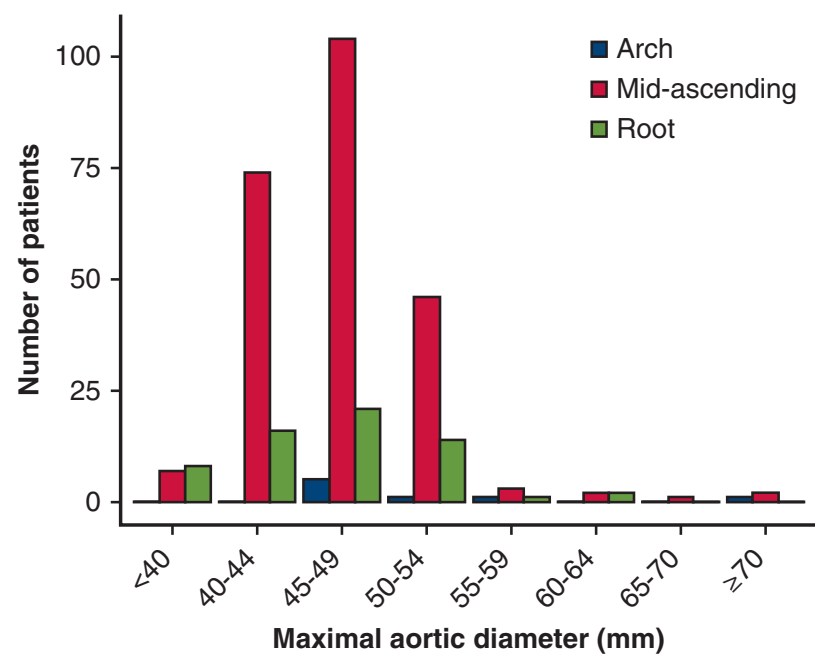

FIGURE 2. Distribution of maximal aortic diameters. aortic diameters greater than $5.5 \mathrm{~cm}$ and between 4 and $5 \mathrm{~cm}$ for various genetically effectuated aortopathies. ${ }^{9-11}$

The ultimate evaluation of a clinical triage algorithm is its clinical effectiveness in producing good clinical outcomes in the treatment limbs. In the present study, we evaluate the effectiveness of our algorithm for triaging ATAAs to surgery (aneurysm size $\geq 5 \mathrm{~cm}$ or a symptomatic aneurysm, ie, chest pain) or to medical management in patients not meeting these criteria.

\section{MATERIALS AND METHODS}

Our database at the Aortic Institute at Yale-New Haven Hospital includes a total of 3455 patients with thoracic aortic disease. Of these, 964 consecutive patients presented electively for the first time to our institution (to author JAE) between January 2011 and February 2017. These patients form the basis for this study.

To constitute a homogenous study population, we excluded patients with concomitant descending or thoracoabdominal aneurysms and patients with chronic $\mathrm{AD}$, traumatic aortic rupture, or significant associated congenital aortic malformations (eg, coarctation of aorta). We identified 781 patients with isolated ATAA who were triaged to surgical intervention or medical management by the senior author (JAE) based on a specific algorithm: surgery for large aortic diameters greater than $5 \mathrm{~cm}$ or for the presence of symptoms (chest pain unexplained by other causes). Other factors commonly contributing to the decision to perform surgery on patients 
TABLE 2. Patients' risk factors

\begin{tabular}{|c|c|c|c|c|c|}
\hline Parameter, n (\%) & $\begin{array}{c}\text { Surgery "noncompliant and } \\
\text { overwhelming comorbidities" } \\
\text { group }(\mathbf{n}=128)\end{array}$ & Medical group $(n=181)$ & Chi-square & $P$ value & Total $(n=309)$ \\
\hline Family history & $47(36.7 \%)$ & $71(39.2 \%)$ & 0.108 & .7428 & $118(38.2 \%)$ \\
\hline Proven & $25(19.5 \%)$ & $48(26.5 \%)$ & 1.66 & .1975 & $73(23.6 \%)$ \\
\hline Possible & $22(17.2 \%)$ & $23(12.7 \%)$ & 0.876 & .3492 & $45(14.6 \%)$ \\
\hline \multicolumn{6}{|l|}{ Connective tissue diseases } \\
\hline Marfan syndrome & - & $7(3.9 \%)$ & - & - & $7(2.3 \%)$ \\
\hline Ehlers-Danlos syndrome & - & $1(0.6 \%)$ & - & - & $1(0.3 \%)$ \\
\hline Hypertension & $77(60.2 \%)$ & $82(45.3 \%)$ & 6.04 & $.014^{*}$ & $159(51.5 \%)$ \\
\hline Chronic kidney disease & $23(18 \%)$ & $8(4.4 \%)$ & 13.785 & $.0002 *$ & $31(10 \%)$ \\
\hline Atrial fibrillation & $21(16.4 \%)$ & $29(16 \%)$ & 0.008 & .928 & $50(16.2 \%)$ \\
\hline Dyslipidemia & $45(35.2 \%)$ & $52(28.7 \%)$ & 1.155 & .2825 & $97(31.4 \%)$ \\
\hline Coronary artery disease & $35(27.3 \%)$ & $29(16 \%)$ & 5.183 & $.0228 *$ & $64(20.7 \%)$ \\
\hline Smoking & $58(45.3 \%)$ & $71(39.2 \%)$ & 0.905 & .3413 & $129(41.8 \%)$ \\
\hline Stroke & $10(7.8 \%)$ & $6(3.3 \%)$ & 2.241 & .1344 & $16(5.2 \%)$ \\
\hline Obstructive sleep apnea & $13(10.2 \%)$ & $17(9.4 \%)$ & 1.711 & .1909 & $30(9.7 \%)$ \\
\hline Obesity & $44(34.4 \%)$ & $54(29.9 \%)$ & 0.520 & .471 & $98(31.7 \%)$ \\
\hline Congestive heart failure & $13(10.2 \%)$ & $10(5.5 \%)$ & 1.711 & .1909 & $23(7.4 \%)$ \\
\hline Diabetes mellitus & $11(8.6 \%)$ & $10(5.5 \%)$ & 0.683 & .4086 & $21(6.8 \%)$ \\
\hline Malignancy & $15(11.7 \%)$ & $33(18.2 \%)$ & 1.953 & .1622 & $48(15.5 \%)$ \\
\hline \multicolumn{6}{|l|}{ Associated conditions } \\
\hline Bicuspid aortic valve & $16(12.5 \%)$ & $14(7.7 \%)$ & 1.437 & .2307 & $30(9.7 \%)$ \\
\hline Bovine $\operatorname{arch}^{23}$ & $13(10.2 \%)$ & $12(6.6 \%)$ & 0.824 & .3639 & $25(8.1 \%)$ \\
\hline Aberrant subclavian artery & $2(1.6 \%)$ & $2(1.1 \%)$ & 0.123 & .726 & $4(1.3 \%)$ \\
\hline Abdominal aortic aneurysm & $8(6.3 \%)$ & $5(2.8 \%)$ & 1.48 & .2237 & $13(4.2 \%)$ \\
\hline Intracranial aneurysms & $2(1.6 \%)$ & $4(2.2 \%)$ & 0.165 & .6845 & $6(1.9 \%)$ \\
\hline \multicolumn{6}{|l|}{ Inflammatory arteritis } \\
\hline Giant cell arteritis & $2(1.6 \%)$ & $3(1.7 \%)$ & 0.004 & .948 & $5(1.6 \%)$ \\
\hline Takayasu arteritis & $1(0.8 \%)$ & $1(0.6 \%)$ & 0.061 & .8049 & $2(0.7 \%)$ \\
\hline
\end{tabular}

*Statistically significant $P$ value.

with diameters 4 to $5 \mathrm{~cm}$ included strong family history of aortic aneurysms and events, ${ }^{6}$ presence of severe connective tissue disease, ${ }^{9}$ or disease of a bicuspid aortic valve.

Patients who underwent prompt surgical repair within 3 months of initial presentation $(\mathrm{n}=472,60 \%)$ were excluded from further outcome analysis. Our main interest was in determining the outcome of unoperated patients triaged to medical or surgical management. Patients triaged to surgery who did not undergo surgery (because of patient refusal, insurance issues, or severe comorbidities) formed the "surgery noncompliant and overwhelming comorbidities group" $(\mathrm{n}=128,16 \%)$. The remaining patients, who from the start were recommended for medical management, constitute the "medical group" $(\mathrm{n}=181,24 \%)$. Ultimately, these 2 groups of patients $(\mathrm{n}=309)$ formed the study population (Figure 1). Medical management consisted mainly of serial follow-up and blood pressure control. We did not routinely prescribe beta-blockers, angiotensin receptor blockers, statins, or other medications for the aneurysm itself.

Radiologic and clinical data were retrospectively accrued from the hospital's electronic medical records system. We used traditional measurements (from axial and coronal images), and not the often misleading
Centerline measurements, in our aortic assessments of the patients in this study. Of the 309 study patients, $221(71.5 \%)$ were male and 88 $(28.5 \%)$ were female. Mean age at presentation was $66.7 \pm 13.6$ years. Patients' characteristics are listed in Table 1.

Primary end points for this study were eventual elective surgical repair, development of an aortic event ( $\mathrm{AD}$, rupture), or death. In the "medical group," eventual elective repair was performed in certain patients who over time developed significant aortic enlargement such that they reached the diameter threshold for surgical intervention or who developed symptoms. In the "surgery noncompliant and overwhelming comorbidities" group, surgery was ultimately performed in certain patients who changed their decision regarding surgery, had their comorbidities controlled, or developed aortic events.

Aortic events were classified as definite and possible, as suggested by Lederle and colleagues, ${ }^{12}$ and were recorded in the 2 groups. Definite aortic events $(\mathrm{n}=11,3.6 \%)$ were defined as the development of aortic rupture or $\mathrm{AD}$, confirmed by an imaging modality, surgical finding during operative repair, or documentation in the death certificate. Possible aortic events $(\mathrm{n}=9,2.9 \%)$ were ascribed to patients whose death certificates classified 
TABLE 3. Logistic regression analyzing the decision to perform surgery

\begin{tabular}{|c|c|c|c|c|}
\hline Variable & Estimate & Odds ratio & $\mathbf{9 5} \%$ Confidence interval & $P$ value* \\
\hline \multicolumn{5}{|l|}{ Aortic diameter $(\mathrm{cm})$} \\
\hline Intercept & -1.78 & 0.168 & $0.00712-1.58$ & .163 \\
\hline $4-5 \mathrm{~cm}$ & 2.21 & 9.16 & $1.6385-173.08$ & $.0397 *$ \\
\hline$\geq 5 \mathrm{~cm}$ & 4.82 & $1.24 \mathrm{E}+02$ & $19.24463-2480.9$ & $.0000208^{*}$ \\
\hline Male sex & -0.507 & 0.603 & $0.33435-1.08$ & .0903 \\
\hline Age & -0.0171 & 0.983 & $0.96176-1$ & .122 \\
\hline Family History & 0.359 & 1.43 & $0.81759-2.52$ & .211 \\
\hline Bicuspid aortic valve & 0.515 & 1.67 & $0.67464-4.17$ & .265 \\
\hline Bovine arch & 0.422 & 1.53 & $0.59212-3.88$ & .375 \\
\hline \multicolumn{5}{|l|}{ Aortic size index $\left(\mathrm{cm} / \mathrm{m}^{2}\right)$} \\
\hline Intercept & 0.1662 & 1.181 & $0.2417-5.884$ & .038 \\
\hline Aortic size index 2.1-3.0 & 1.0289 & 2.798 & $1.5359-5.259$ & $.00101 *$ \\
\hline Aortic size index $\geq 3.0$ & 4.5379 & $9.349 \mathrm{E}+01$ & $15.3538-1836.884$ & $.0000451^{*}$ \\
\hline Male sex & 0.4395 & 1.552 & $0.8543-2.878$ & .155 \\
\hline Age & -0.0256 & 0.975 & 0.9533-0.996 & $.0214^{*}$ \\
\hline Family History & -0.014 & 0.986 & $0.5797-1.671$ & .959 \\
\hline Bicuspid aortic valve & -0.0066 & 0.993 & $0.4137-2.359$ & .988 \\
\hline Bovine arch & 0.4486 & 1.566 & $0.6475-3.795$ & .315 \\
\hline \multicolumn{5}{|l|}{ Aortic height index $(\mathrm{cm} / \mathrm{m})$} \\
\hline Intercept & 0.02169 & 1.022 & $0.175-5.917$ & .981 \\
\hline Aortic height index 2.4-3.1 & 1.817154 & 6.154 & $2.671-16.281$ & $.0000668^{*}$ \\
\hline Aortic height index $\geq 3.1$ & 6.086112 & $4.397+02$ & $62.52-9305.261$ & $.000000229^{*}$ \\
\hline Male sex & 0.476626 & 1.611 & $0.87-3.06$ & .136 \\
\hline Age & -0.038305 & 0.962 & $0.939-0.985$ & $.00157 *$ \\
\hline Family history & 0.147699 & 1.159 & $0.669-2.005$ & .597 \\
\hline Bicuspid aortic valve & 0.000273 & 1 & $0.406-2.439$ & 1 \\
\hline Bovine arch & 0.370199 & 1.448 & $0.59-3.566$ & .415 \\
\hline
\end{tabular}

*Statistically significant $P$ value.

their cause of death as "cardiac" without specifying the precise cause. One patient died at an outside hospital, and the partner was informed that the cause of death was "aortic"; this patient was included in the "definite events" category.

Survival follow-up of patients was performed according to the Yale Aortic Institute Methodology described previously ${ }^{13}$ through October 2017. Follow-up was complete in 301 patients $(97.4 \%)$, with a mean follow-up of $38.9 \pm 23$ months. Data on the vital status and causes of death were further validated by obtaining death certificates from the State Vital Records Office at the Connecticut Department of Public Health to confirm the causes of death. For living patients who did not follow up with our center, efforts were made to obtain recent medical records from their referring physicians and primary care providers. In patients who were lost to followup $(\mathrm{n}=8,2.6 \%)$, the follow-up period for analysis ended upon their last clinical encounter.

Family history was considered positive if a relative of the patient had a thoracic aortic aneurysm or AD, confirmed on an imaging study, intraoperatively, or on autopsy, including affected relatives alive or who died. For statistical analysis, we used only patients with proven family history. The study was approved by the Human Investigation Committee of the Yale University School of Medicine.

\section{Statistical Methods}

Statistical analysis was performed using R 3.4.1 (R Foundation for Statistical Computing, Vienna, Austria). ${ }^{14}$ Continuous variables are presented as mean \pm standard deviation, and categorical variables are presented as values and percentages. The "zero time" (when the follow-up clock is started) is the time of the initial evaluation. Kaplan-Meier curves were used to display the survival probability in both groups, and log-rank test was used to determine the significance of outcome differences. Cumulative risks for definite, possible, and total events were plotted over the follow-up period and were stratified by maximal aortic diameter.

Cox-proportional hazards regression models were used to conduct multivariate analysis for aortic events, and logistic regression models were used to obtain odds ratios for the factors affecting decision-making.

The receiver operating characteristic method was used to assess the ability of the maximal aortic diameter to predict adverse aortic events within 1 year. ${ }^{15}$ Absolute aortic diameter and indexed diameters (aortic size index [ASI]/aortic height index [AHI]) were evaluated.

\section{RESULTS}

\section{Patients' Characteristics}

Data on the location and maximal aortic diameters were obtained using computed tomography in 250 patients $(80.9 \%)$, magnetic resonance imaging in 18 patients $(5.8 \%)$, and transthoracic echocardiography/transesophageal echocardiography in 41 patients $(12.3 \%)$. The location of maximal aortic diameter in the majority of patients was in the mid-ascending portion $(\mathrm{n}=239,77.4 \%)$ in comparison with the root $(\mathrm{n}=62,20 \%)$ and the proximal aortic arch $(\mathrm{n}=8,2.6 \%)$. The distribution of maximal aortic 
TABLE 4. Patient outcomes

\begin{tabular}{|c|c|c|c|c|c|}
\hline Outcome, n (\%) & $\begin{array}{c}\text { Surgery "noncompliant and } \\
\text { overwhelming } \\
\text { comorbidities" group }\end{array}$ & Medical group & Chi-square & $P$ value & Total $(\mathbf{n}=309)$ \\
\hline Eventual repair & $21(16.4 \%)$ & $15(8.3 \%)$ & 4.045 & $.0443^{*}$ & $36(11.7 \%)$ \\
\hline $\begin{array}{l}\text { Mean diameter at time of } \\
\text { repair }\end{array}$ & $4.9 \pm 1.1$ & $4.8 \pm 0.2$ & - & - & $4.9 \pm 0.7$ \\
\hline Size increased & - & $10(5.5 \%)$ & & & - \\
\hline Symptoms developed & - & $5(2.8 \%)$ & & & - \\
\hline Inoperable & $44(34.4 \%)$ & - & & & - \\
\hline Refusal of surgery & $79(61.7 \%)$ & - & & & - \\
\hline Lost to follow-up & $5(3.9 \%)$ & $3(1.7 \%)$ & 0.744 & .3884 & $8(2.6 \%)$ \\
\hline Death & $20(15.6 \%)$ & $6(3.3 \%)$ & 13.19 & $.0003^{*}$ & $26(8.4 \%)$ \\
\hline Aortic & $7(5.5 \%)$ & $0(0 \%)$ & & & $7(2.3 \%)$ \\
\hline Possible aortic & $8(6.3 \%)$ & $1(0.6 \%)$ & 8.087 & $.0045^{*}$ & $9(2.9 \%)$ \\
\hline Nonaortic & $5(3.9 \%)$ & $5(2.8 \%)$ & 0.3132 & .575693 & $10(3.2 \%)$ \\
\hline Aortic event & $17(13.3 \%)$ & $3(1.7 \%)$ & 14.87 & $.0001^{*}$ & $20(6.5 \%)$ \\
\hline Definite & $9(7 \%)$ & $2(1.1 \%)$ & 4.801 & $.0284^{*}$ & $11(3.6 \%)$ \\
\hline Possible & $8(6.3 \%)$ & $1(0.6 \%)$ & 8.087 & $.0045^{*}$ & $9(2.9 \%)$ \\
\hline No surgery/no event & $72(56.3 \%)$ & $155(85.6 \%)$ & 31.720 & $<.0001 *$ & $227(73.5 \%)$ \\
\hline
\end{tabular}

*Statistically significant $P$ value.

diameters is depicted in Figure 2, with most patients in the 4.5 to $5 \mathrm{~cm}$ category.

Analysis of the patients' risk factors (Table 2) showed that a large proportion of our cohort were smokers and hypertensive $(51.5 \%$ and $41.8 \%$, respectively), whereas diabetes mellitus was observed in only 21 patients $(6.8 \%)$, consistent with previous observations. ${ }^{16}$
Compared with patients in the medical group, patients in the surgery noncompliant and overwhelming comorbidities group suffered more from hypertension $(60.2 \%$ vs $45.3 \%$, $P=.01)$, chronic kidney disease $(18 \%$ vs $4,4 \%, P<.001)$, and coronary artery disease $(27.3 \%$ vs $16 \%, P=.02)$. A significant number of patients had a positive or a likely family history $(38 \%)$, in line with the concept that thoracic

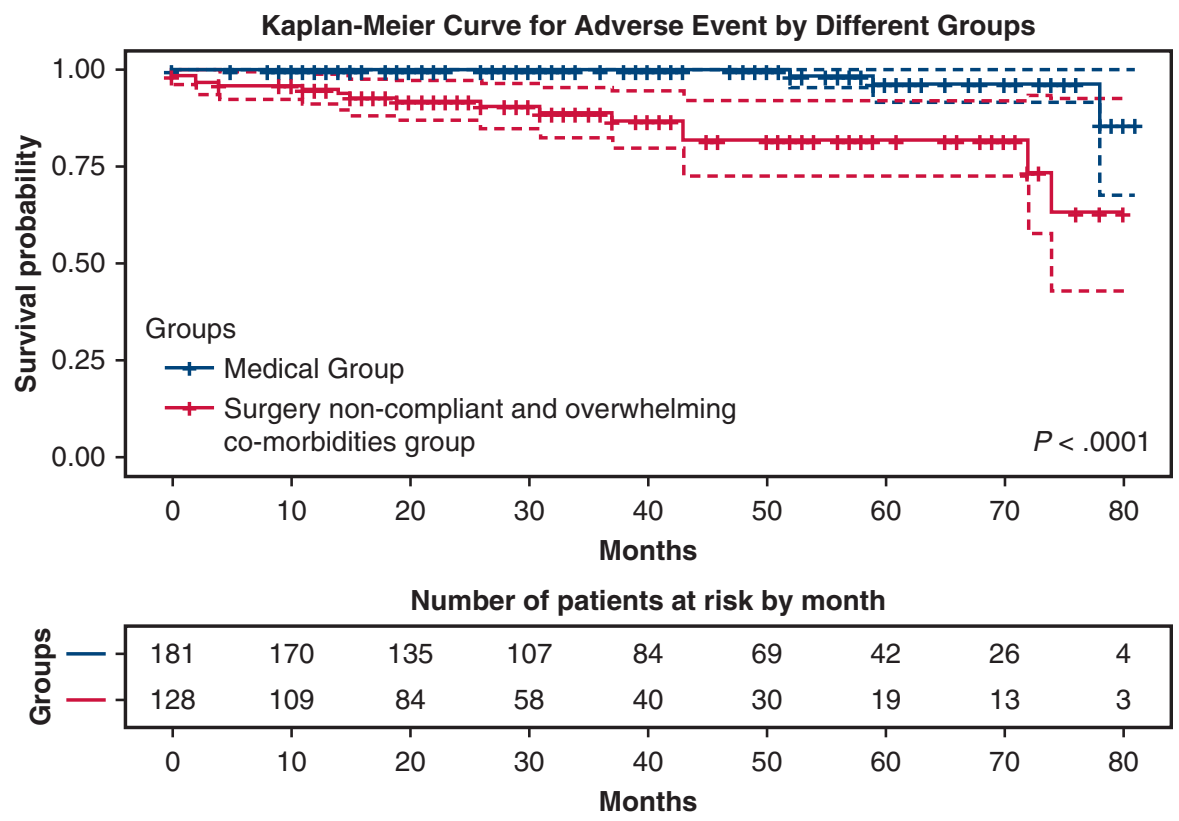

FIGURE 3. Kaplan-Meier curve for adverse events in surgical and medical groups. 
aortic aneurysms exhibit a strong familial aggregation pattern. ${ }^{17-19}$

\section{Triaging Algorithm}

Logistic regression of the triaging algorithm was used to examine the effects of patient characteristics on the decision making, analyzing the factors that raise the odds of patients being triaged to surgery (Table 3). Analysis of the model confirmed the importance of the maximal aortic diameter on treatment choice, showing that patients were more likely to be selected for surgery in the group with aortic diameters $5.0 \mathrm{~cm}$ or greater compared with patients with aortic diameters less than $4.0 \mathrm{~cm}(P<.001)$. This analysis provides confirmation that the algorithm was applied as intended.

By indexing the aortic diameter to body habitus, similar models were constructed using the ASI and AHI. Compared with patients who were in the ASI categories less than $2.1 \mathrm{~cm} / \mathrm{m}^{2}$, patients were more likely to be selected for surgery in categories 2.1 to $3.0 \mathrm{~cm} / \mathrm{m}^{2}(P=.001)$ and $3.0 \mathrm{~cm} / \mathrm{m}^{2}$ or more $(P<.001)$. Similar results were obtained by using the AHI, with patients in groups 2.4 to $3.1 \mathrm{~cm} / \mathrm{m}$ and $3.1 \mathrm{~cm} / \mathrm{m}$ or more being more likely to be selected for surgery, compared with patients who were in AHI categories less than $2.4 \mathrm{~cm} / \mathrm{m}(P<.001)$. As might be anticipated, patients with older age were less likely to be selected for surgery, as depicted in the last model using the AHI $(P=.001)$.

\section{Outcomes}

Significant differences in outcomes were found between the "surgery noncompliant and overwhelming comorbidities" group and the "medical" group in terms of aortic events (17 vs $3, P<.001)$, eventual repair (21 vs 15 , $P=.04)$, and death $(20$ vs $6, P<.001)$. In patients who underwent prompt surgery, hospital mortality occurred in 5 of 472 patients $(1 \%)$, and postdischarge all-cause mortality occurred in 16 patients $(3.4 \%)$. The mean follow-up in the 2 groups is similar ("noncompliant and overwhelming comorbidities" group 34.6 months, "medical" group 42 months). A summary of patient outcomes is outlined in (Table 4).

- Surgery noncompliant and overwhelming comorbidities group

Of the total cohort, 128 patients $(16 \%)$ met the surgical intervention criteria, based on symptoms and aortic diameter, but they refused surgery $(n=79$, $61.72 \%)$ or were inoperable at that time $(n=44$, $34.38 \%$ ), constituting the "surgery noncompliant and overwhelming comorbidities group." Among the 44 patients who were "inoperable," 10 patients $(7.8 \%)$ had severe comorbidities that hindered the
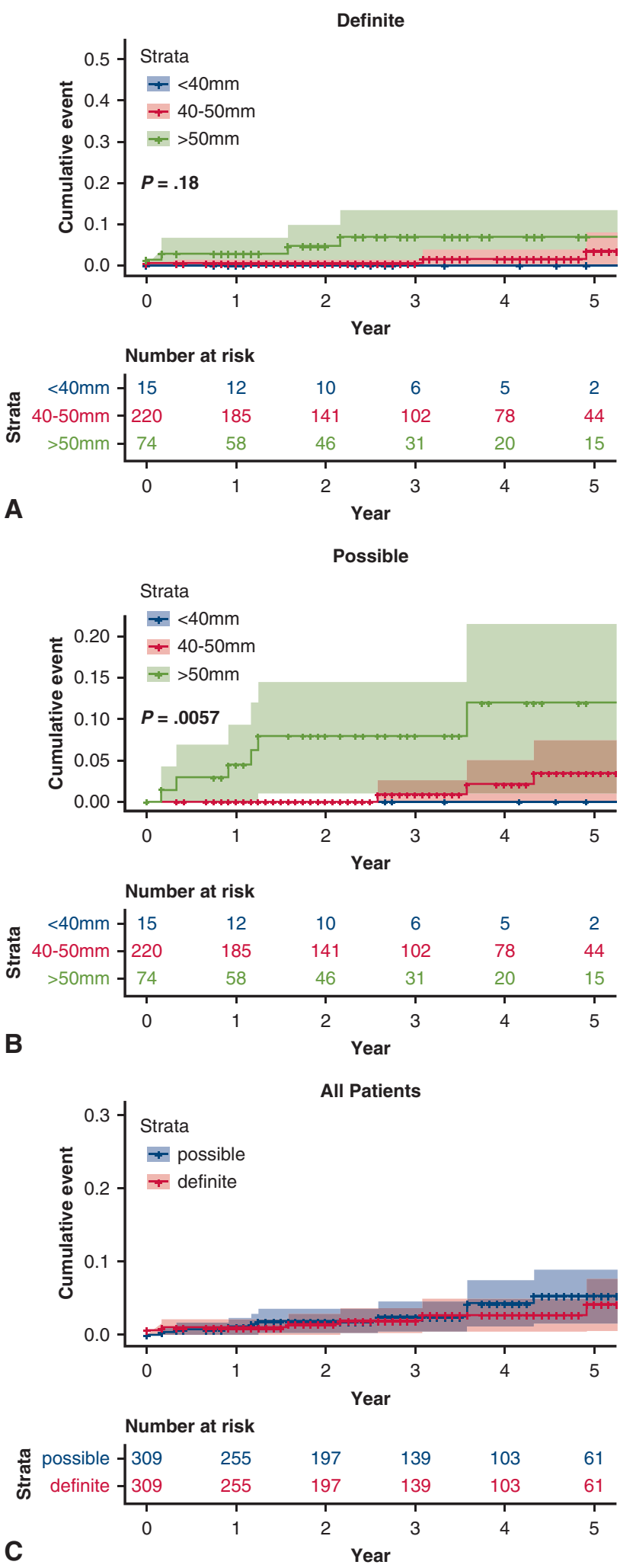

FIGURE 4. Cumulative risk of adverse events: definite (A), possible (B) "stratified by maximum aortic diameter," and all events (C). Confidence intervals are depicted by the shaded areas. 
TABLE 5. Cox proportional hazard regressions on adverse aortic events

\begin{tabular}{|c|c|c|c|c|}
\hline Type of event & Variable & Coefficient & $\begin{array}{l}\text { Hazard ratio }(95 \% \\
\text { confidence interval) }\end{array}$ & $P$ value* \\
\hline \multicolumn{5}{|c|}{ Definite $(\mathrm{n}=11)$} \\
\hline & Maximal diameter & 0.518 & $1.68(0.92168-3.057)$ & .0904 \\
\hline & Age & $-5.92 \mathrm{E}-03$ & $0.994(0.94522-1.046)$ & .8179 \\
\hline & Male sex & -1.31 & $0.271(0.07044-1.044)$ & .0578 \\
\hline & Chronic kidney disease & 0.897 & $2.45(0.46596-12.896)$ & .2898 \\
\hline & Stroke & -0.0183 & $1.14 \mathrm{E}-08(1.0638-19.507)$ & .9986 \\
\hline & Coronary artery disease & 0.0822 & $1.09(0.21201-5.56)$ & .9214 \\
\hline & Hypertension & 0.688 & 1.99 (0.43683-9.054) & .374 \\
\hline \multicolumn{5}{|l|}{ Possible $(\mathrm{n}=9)$} \\
\hline & Maximal diameter & 1.09151 & $2.97876(1.6439-5.398)$ & $.00032 *$ \\
\hline & Age & 0.01073 & $1.01079(0.9508-1.075)$ & .73111 \\
\hline & Male sex & -0.25848 & $0.77222(0.1535-3.884)$ & .75381 \\
\hline & Chronic kidney disease & 1.51631 & $4.55537(1.0638-19.507)$ & $.04103^{*}$ \\
\hline & Stroke & 1.788 & $5.97746(1.001-35.694)$ & .04987 \\
\hline & Coronary artery disease & 1.49423 & $4.45591(0.9391-21.143)$ & .05999 \\
\hline & Hypertension & 0.52855 & $1.69647(0.2299-12.517)$ & .60422 \\
\hline \multicolumn{5}{|c|}{ Total events $(n=20)$} \\
\hline & Maximal diameter & 0.784485 & $2.191277(1.4436-3.326)$ & $.000229 *$ \\
\hline & Age & -0.003316 & $0.996689(0.9586-1.036)$ & .867551 \\
\hline & Male sex & -0.895619 & $0.408355(0.1548-1.077)$ & .070261 \\
\hline & Chronic kidney disease & 1.127614 & $3.088279(1.0575-9.019)$ & $.039184 *$ \\
\hline & Stroke & 0.715267 & $2.044733(0.4376-9.554)$ & .363177 \\
\hline & Coronary artery disease & 0.86051 & $2.364367(0.7965-7.018)$ & .121105 \\
\hline & Hypertension & 0.560792 & $1.752059(0.5326-5.763)$ & .355972 \\
\hline
\end{tabular}

*Statistically significant $P$ value.

decision for surgery, and 15 patients $(11.7 \%)$ were aged more than 80 years and chose to continue with medical management rather than surgery. Nine patients $(7 \%)$ were referred for bariatric surgery before aortic repair because of extreme obesity; however, they did not go through with it, and $10 \mathrm{pa}-$ tients $(7.8 \%)$ had active treatments for cancer or human immunodeficiency virus that required completion before surgical aortic repair.

In this group, mean aortic diameter was $5 \pm 0.5 \mathrm{~cm}$. Thirteen patients $(10.1 \%)$ had aortic diameters $5.5 \mathrm{~cm}$ or greater, and 74 patients $(57.8 \%)$ had aortic diameters $5 \mathrm{~cm}$ or greater. Seventeen patients $(21.76 \%)$ developed aortic events $(9$ definite and 8 possible), of which 15 events $(88.2 \%)$ were fatal and 6 events $(35.2 \%)$ occurred within 1 year of presentation.

Eventual aortic repair was carried out in 21 cases $(16.4 \%)$, in patients who changed their mind regarding surgery $(\mathrm{n}=12,75.1 \%)$, had their co- morbidities controlled $(\mathrm{n}=7,33.3 \%)$, or developed aortic events $(\mathrm{AD})(\mathrm{n}=2,9.5 \%)$.

Twenty patients $(15.6 \%)$ died, of whom $7(5.5 \%)$ had confirmed aortic deaths (3 ADs, 4 aortic ruptures), 8 patients $(6.3 \%)$ had possible aortic deaths, and 5 patients $(3.9 \%)$ had confirmed nonaortic deaths (2 myocardial infarctions, 1 aspiration pneumonia, 1 ruptured appendix and septicemia, and 1 cardiogenic shock).

Five patients $(3.9 \%)$ were lost to follow-up, and only 72 patients $(56.3 \%)$ had a benign course of followup, free of aortic events, aortic surgical intervention, or death.

- Medical management group

In the medical management group $(\mathrm{n}=181,24 \%)$, mean aortic diameter was smaller $(4.45 \pm 0.4 \mathrm{~cm})$. Three patients $(1.7 \%)$ developed aortic events $(2 \mathrm{ADs}$ and 1 possible event in the death certificate), none of which occurred within 
TABLE 6. Receiver operating curve for baseline size indices of the aorta to predict adverse aortic events within 1 year

\begin{tabular}{|c|c|c|c|c|c|c|}
\hline & \multicolumn{3}{|c|}{ Definite aortic events } & \multicolumn{3}{|c|}{ Possible aortic events } \\
\hline & $\overline{\mathbf{A U C}}$ & $95 \% \mathrm{CI}$ & $P$ value & $\mathbf{A U C}$ & $95 \%$ CI & $P$ value \\
\hline Diameter & 0.8355 & $0.7245-0.9465$ & $.0226^{*}$ & 0.9831 & $0.9630-1.0000$ & $.0019 *$ \\
\hline ASI & 0.5169 & $0.0525-0.9136$ & .4611 & 0.8772 & $0.6392-1.0000$ & $.0124 *$ \\
\hline AHI & 0.8166 & $0.6735-0.9597$ & $.0298 *$ & 0.9291 & $0.7245-1.0000$ & $.0053 *$ \\
\hline
\end{tabular}

$A U C$, Area under the curve; $C I$, confidence interval; $A S I$, aortic size index; $A H I$, aortic height index. *Statistically significant $P$ value.

the first year. Six patients died, none of whom had a confirmed aortic death. Five patients had a confirmed nonaortic death (1 heart failure exacerbation, 1 chronic obstructive pulmonary disease exacerbation, 1 cerebral hemorrhage, 1 septic shock, and 1 metastatic bladder cancer), and 1 patient had a possible aortic death listed on the death certificate. Eventual elective repair was performed in patients whose aortic diameter enlarged significantly, meeting the surgical criterion $(\mathrm{n}=10$, $5.5 \%)$, or who developed symptoms $(\mathrm{n}=5$, $2.8 \%)$. Three patients $(1.7 \%)$ were lost to followup, and the majority of patients $(n=155,85.6 \%)$ continued to do well, neither requiring surgery nor experiencing any aortic events.

Kaplan-Meier survival analysis for adverse events (death, aortic events, repair) in both groups is depicted in Figure 3. The curve shows that survival probability was significantly better in the "medical" group throughout the whole follow-up period, compared with the surgery noncompliant and overwhelming comorbidities group $(P<.001)$.

\section{Estimated Effect of Ascending Aortic Aneurysm} Size on Risk of Complication

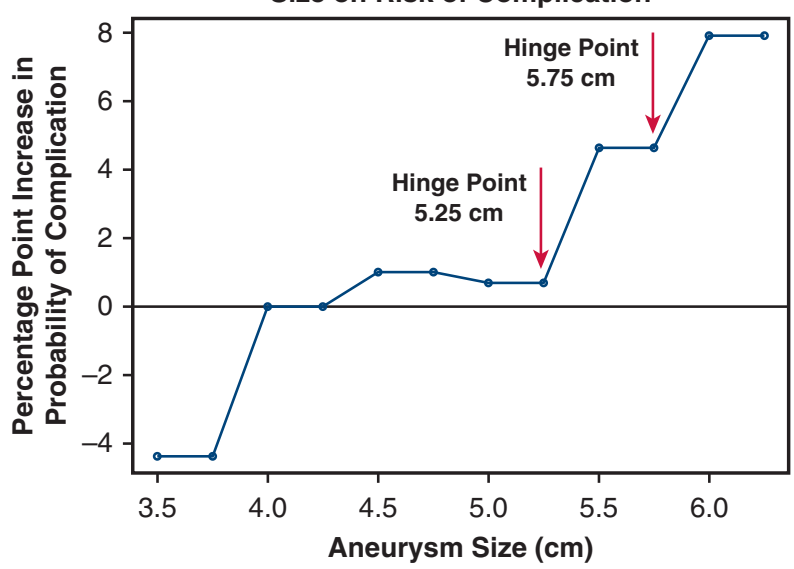

FIGURE 5. Estimated probability of rupture or dissection of the ascending aorta by aneurysm size, based on previous data from our group. Reprinted with permission from Zafar et al. ${ }^{8}$

\section{Aortic Events}

Overall, 20 patients experienced aortic events, 11 definite and 9 possible. Of these, 11 patients were female and 9 were male. The risk of adverse aortic events is depicted in Figure 4, showing an increased cumulative risk of events in patients with maximal aortic diameters greater than $5 \mathrm{~cm}$, at 1,3 , and 5 years.

- Surgery noncompliant and overwhelming comorbidities group

In the surgery noncompliant and overwhelming comorbidities group, definite aortic events occurred in 9 patients ( 5 type A ADs and 4 aortic ruptures) at a mean duration of $14 \pm 13$ months. Mean aortic diameter in the definite event group was $5.2 \pm 0.57 \mathrm{~cm}$. Five events occurred within 12 months of the first encounter, and aortic events were fatal in 7 patients. The remaining 2 patients underwent emergency repair for acute type-A AD and continued to do well during the follow-up.

Eight patients had possible aortic events at a mean duration of $20 \pm 16$ months, all of whom died. Mean aortic diameter in patients with possible events was $5.7 \pm 0.4 \mathrm{~cm}$. Three events occurred within 12 months of the first encounter. All patients had a cardiac cause of death on the death certificate.

- Medical management group

In the "medical" group, 2 patients developed AD (1 type A and 1 type B, both managed surgically, and continued to do well during the follow-up). One patient had a cardiac death listed on his death certificate and was classified as a possible aortic death. The mean maximal aortic diameter in these patients was $4.5 \pm 0.4 \mathrm{~cm}$, and events occurred at a mean duration of $34 \pm 20$ months.

Multivariable regression analysis of the total aortic events (Table 5) showed that the maximum aortic diameter was significantly associated with a higher risk of developing an event (hazard ratio, $2.19 ; P<.001$ ). Higher risk was also observed in patients with chronic kidney disease (hazard ratio, $3 ; P=.03)$. 

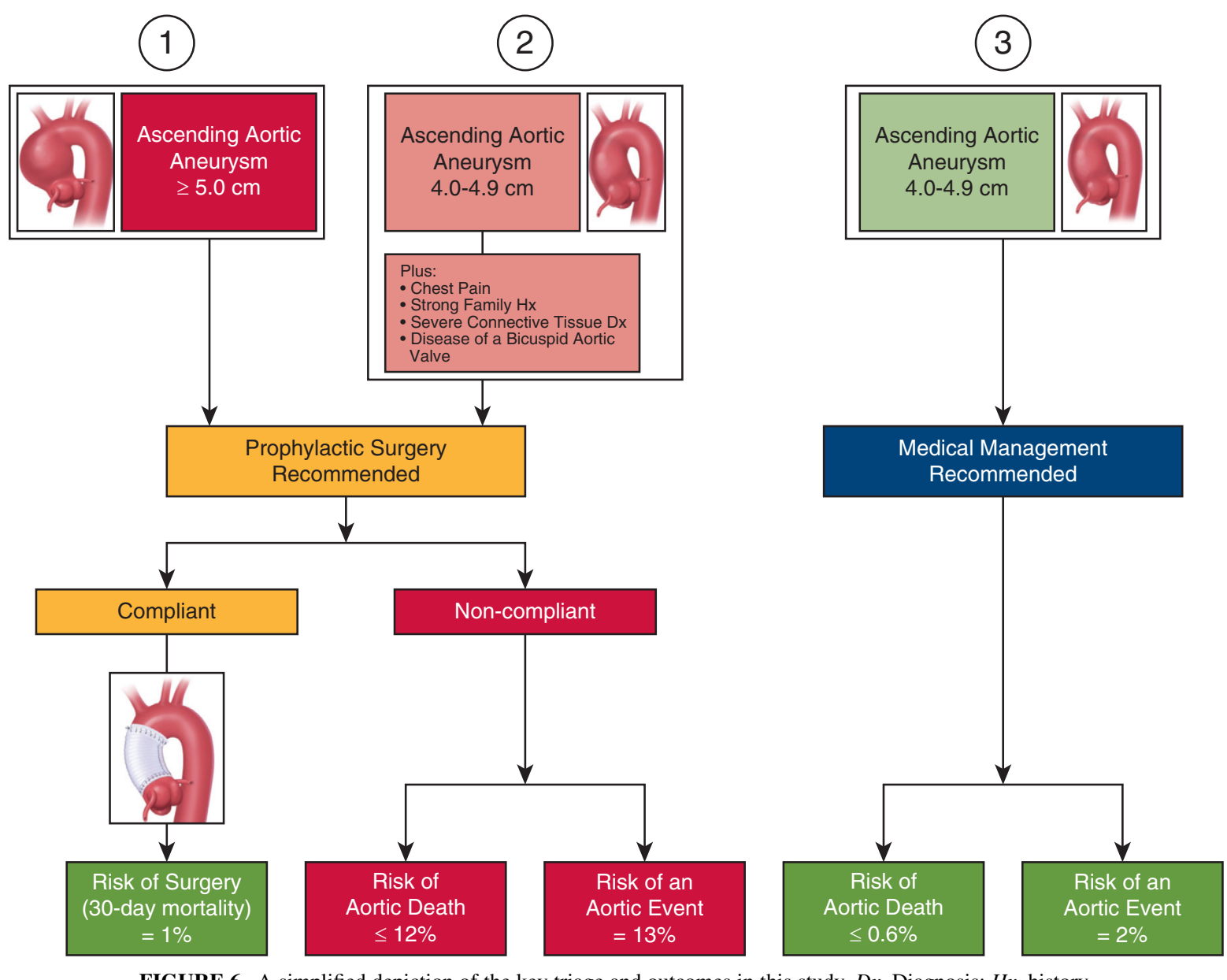

FIGURE 6. A simplified depiction of the key triage and outcomes in this study. $D x$, Diagnosis; $H x$, history.

Receiver operating characteristic analysis was used to assess the sensitivity of maximal aortic diameter as a predictor of adverse aortic events within 1 year (Table 6). The model yielded an area under the curve of 0.836 for definite aortic events $(95 \%$ confidence interval, 0.72-0.95; $P=.02)$ and 0.983 for possible events $(95 \%$ confidence interval, $0.963-1.00 ; P=.001)$. Likewise, high area under the curve was found while using the AHI for both definite and possible events ( $P=.03$ and .005 , respectively), while only significantly high for possible events when using the ASI $(P=.01)$ compared with definite events $(P=.46)$.

\section{DISCUSSION}

The most recent practice guidelines from the American College of Cardiology/American Heart Association recommend surgical repair of asymptomatic ascending aortic aneurysms at diameters $5.5 \mathrm{~cm}$ or greater (Class IC). Repair at an even smaller diameter is warranted in symptomatic patients, patients with a strong positive family history of aortic aneurysms, and patients with aggressive connective tissue diseases such as Marfan syndrome, Ehlers-Danlos syndrome, or Loeys-Dietz syndrome. In expert centers that can deliver ascending aortic surgery at low risk, surgery at $5 \mathrm{~cm}$ (rather than $5.5 \mathrm{~cm}$ ) is generally accepted. ${ }^{20}$

In 1997, we first reported on the natural history of the thoracic aorta, ${ }^{4}$ with the logistic regression model displaying a "hinge point" at $6 \mathrm{~cm}$, at which the risk of rupture or dissection increased dramatically. Recent revisiting of these calculations, with a much larger patient cohort, proved the dominating effect of aortic size on clinical outcome. This larger analysis revealed 2 new hinge points of increased risk at 5.25 to $5.5 \mathrm{~cm}$, suggesting that a "left shift" of this diameter for prophylactic surgical intervention might be necessary-to $5 \mathrm{~cm}$ rather than $5.5 \mathrm{~cm}$ (Figure 5). ${ }^{8,21}$ This newly recommended diameter is indeed the one used in the clinical algorithm applied in the present study.

In our study, we sought to evaluate the clinical outcomes and effectiveness of a straightforward patient triaging approach for ATAA to surgery or to medical management (Figure 6). We used the aortic size criterion of $5 \mathrm{~cm}$ in our algorithm. This is lower than the $5.5 \mathrm{~cm}$ used in recent consensus documents. However, 


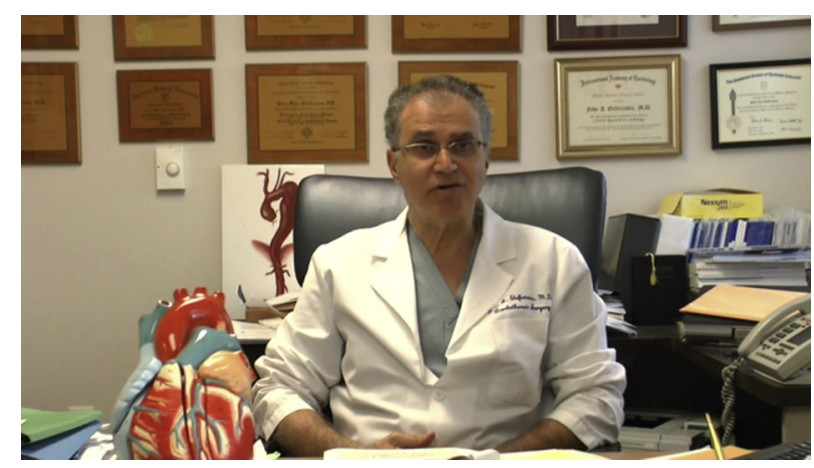

VIDEO 1. Summary of the key points of the study and important clinical implications. Video available at: https://www.jtcvs.org/article/S00225223(18)32927-1/fulltext.

our most recent data support such a lower criterion. These data are presented in detail in an article in the Journal. $^{22}$

The core of our algorithm is its simplicity: surgery for large or symptomatic aneurysms. The algorithm worked well in the clinical setting of new patients presenting for evaluation and management decision making. Patients triaged to medical management did well, with a low rate of aortic events. Patients triaged to surgery who could not undergo operation, for a variety of reasons, did poorly, with many aortic events and a high mortality. The triage algorithm did exactly what it needed to do-weeding out patients with high aortic risk who need surgical intervention to remain safe.

Aortic natural history studies face many obstacles. Adequate follow-up on patients can sometimes be difficult to complete. Further, because of the high fatality of aortic complications, many patients die "suddenly" before or just after reaching an emergency department; such patients are frequently misdiagnosed as myocardial infarctions. Therefore, ascertaining the true cause of death for many patients can become problematic. In our study, we accounted for this variable by classifying death and aortic events into "possible" and "definite" categories, as suggested by Lederle and colleagues. ${ }^{12}$

Our results showed distinctly worse outcomes in patients who did not follow the surgical recommendation. These outcomes in terms of mortality, development of events, or eventual surgery were significantly poorer in the surgery noncompliant and overwhelming comorbidities group, compared with patients who were triaged to medical treatment from the start. This shows that the algorithm was functioning in the clinical setting, correctly identifying the patients at risk for aortic events.

Accessory analyses by regression techniques and receiver operating characteristic confirmed prior work demonstrating an overwhelmingly strong impact of aortic size on rupture and dissection rates.

\section{Study Limitations}

This study was limited by its retrospective nature by the referral bias inherent in a single study center and in the specialized aortic referral nature of our center. Triaging of patients, although highly dependent on diameter, supplemented by symptoms, was certainly affected as well by clinical judgment and instinct, which cannot be specified or quantified. Because the "surgery noncompliant and overwhelming comorbidities" group included not only patients refusing surgery but also patients with comorbidities precluding safe surgery or advanced age, it is possible that this factor on its own biased against survival. With extreme critical caution in classifying an event as "aortic," the number of such events may have been underestimated.

\section{CONCLUSIONS}

We have evaluated the clinical effectiveness of the specific triaging algorithm for thoracic ascending aortic aneurysms (see summary in Video 1), permitting the following conclusions:

- Patients who did not follow the surgical recommendations experienced poorer outcomes in terms of death, adverse events, and eventual surgical repair.

- Patients who were triaged to medical treatment did well, with significantly lower mortality, and had no definite aortic events.

- The clinical algorithm, based on aortic diameter and symptoms (pain), functioned extremely effectively in a clinical setting.

\section{Webcast}

You can watch a Webcast of this AATS meeting presentation by going to: https://aats.blob.core.windows.net/ media/18May01/28ABC\%202.Aortic\%20Endovascular/ S86\%20-\%20Part\%202/S86_4_webcast_045149735.mp4.

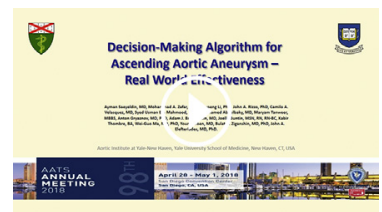

\section{Conflict of Interest Statement}

Authors have nothing to disclose with regard to commercial support.

\section{References}

1. Saeyeldin AA, Velasquez CA, Mahmood SUB, Brownstein AJ, Zafar MA, Ziganshin BA, et al. Thoracic aortic aneurysm: unlocking the "silent killer" secrets. Gen Thorac Cardiovasc Surg. 2019;67:1-11. 
2. Elefteriades JA, Rizzo JA. Epidemiology: incidence, prevalence, and trends. In: Elefteriades JA, ed. Acute Aortic Diseases. 1st ed. Boca Raton: CRC Press; 2007: 89-98.

3. Moriwaki Y, Tahara Y, Kosuge T, Suzuki N. Etiology of out-of-hospital cardiac arrest diagnosed via detailed examinations including perimortem computed tomography. J Emerg Trauma Shock. 2013;6:87-94.

4. Coady MA, Rizzo JA, Hammond GL, Mandapati D, Darr U, Kopf GS, et al. What is the appropriate size criterion for resection of thoracic aortic aneurysms? J Thorac Cardiovasc Surg. 1997;113:476-91.

5. Davies RR, Gallo A, Coady MA, Tellides G, Botta DM, Burke B, et al. Novel measurement of relative aortic size predicts rupture of thoracic aortic aneurysms. Ann Thorac Surg. 2006;81:169-77.

6. Elefteriades JA. Natural history of thoracic aortic aneurysms: indications for surgery, and surgical versus nonsurgical risks. Ann Thorac Surg. 2002;74:S1877-80; discussion S92-8.

7. Davies RR, Goldstein LJ, Coady MA, Tittle SL, Rizzo JA, Kopf GS, et al. Yearly rupture or dissection rates for thoracic aortic aneurysms: simple prediction based on size. Ann Thorac Surg. 2002;73:17-28.

8. Zafar MA, Li Y, Rizzo JA, Charilaou P, Saeyeldin A, Velasquez CA, et al. Height alone, rather than body surface area, suffices for risk estimation in ascending aortic aneurysm. J Thorac Cardiovasc Surg. 2018;155:1938-50.

9. Hiratzka LF, Bakris GL, Beckman JA, Bersin RM, Carr VF, Casey DE, et al. 2010 ACCF/AHA/AATS/ACR/ASA/SCA/SCAI/SIR/STS/SVM guidelines for the diagnosis and management of patients with thoracic aortic disease. A Report of the American College of Cardiology Foundation/American Heart Association Task Force on practice guidelines, American Association for Thoracic Surgery, American College of Radiology, American Stroke Association, Society of Cardiovascular Anesthesiologists, Society for Cardiovascular Angiography and Interventions, Society of Interventional Radiology, Society of Thoracic Surgeons, and Society for Vascular Medicine. Circulation. 2010;121:e266-369.

10. Erbel R, Aboyans V, Boileau C, Bossone E, Bartolomeo RD, Eggebrecht H, et al. 2014 ESC Guidelines on the diagnosis and treatment of aortic diseases. Document covering acute and chronic aortic diseases of the thoracic and abdominal aorta of the adult. The Task Force for the Diagnosis and Treatment of Aortic Diseases of the European Society of Cardiology (ESC). Eur Heart J. 2014;35: 2873-926.

11. Brownstein AJ, Ziganshin BA, Kuivaniemi H, Body SC, Bale AE, Elefteriades JA. Genes associated with thoracic aortic aneurysm and dissection: an update and clinical implications. Aorta (Stamford). 2017;5:11-20.

12. Lederle FA, Johnson GR, Wilson SE, Ballard DJ, Jordan WD Jr, Blebea J, et al Rupture rate of large abdominal aortic aneurysms in patients refusing or unfit for elective repair. JAMA. 2002;287:2968-72.

13. Peterss S, Charilaou P, Ziganshin BA, Elefteriades JA. Assessment of survival in retrospective studies: The Social Security Death Index is not adequate for estimation. J Thorac Cardiovasc Surg. 2017;153:899-901.

14. R Core Team. R: A Language and Environment for Statistical Computing. 3.4.1 ed. Vienna, Austria: R Core Team; 2017.

15. DeLong ER, DeLong DM, Clarke-Pearson DL. Comparing the areas under two or more correlated receiver operating characteristic curves: a nonparametric approach. Biometrics. 1988;44:837-45.

16. Prakash SK, Pedroza C, Khalil YA, Milewicz DM. Diabetes and reduced risk for thoracic aortic aneurysms and dissections: a nationwide case-control study. J Am Heart Assoc. 2012;1(2).

17. Coady MA, Davies RR, Roberts M, Goldstein LJ, Rogalski MJ, Rizzo JA, et al. Familial patterns of thoracic aortic aneurysms. Arch Surg. 1999;134:361-7.

18. Albornoz G, Coady MA, Roberts M, Davies RR, Tranquilli M, Rizzo JA, et al. Familial thoracic aortic aneurysms and dissections-incidence, modes of inheritance, and phenotypic patterns. Ann Thorac Surg. 2006;82:1400-5.

19. Elefteriades JA. Thoracic aortic aneurysm: reading the enemy's playbook. Yale $J$ Biol Med. 2008;81:175-86.

20. Borger MA, Fedak PWM, Stephens EH, Gleason TG, Girdauskas E, Ikonomidis JS, et al. The American Association for Thoracic Surgery consensus guidelines on bicuspid aortic valve-related aortopathy: executive summary. $J$ Thorac Cardiovasc Surg. 2018;156:473-80.

21. Gryaznov AA, Ziganshin BA, Elefteriades JA. Time to move to earlier intervention for thoracic aortic aneurysm? J Struct Heart Dis. 2017;2:10-22.

22. Ziganshin BA, Zafar M, Elefteriades AJ. Descending threshold for ascending aortic aneurysmectomy: is it time for a "left-shift" in guidelines? J Thorac Cardiovasc Surg. 2018;157:37-42.
23. Dumfarth J, Chou AS, Ziganshin BA, Bhandari R, Peterss S, Tranquilli M, et al. Atypical aortic arch branching variants: a novel marker for thoracic aortic disease. J Thorac Cardiovasc Surg. 2015;149:1586-92.

Key Words: thoracic aorta, thoracic aortic aneurysm, natural history, aortic dissection, aortic rupture, clinical outcomes, clinical care, decision making

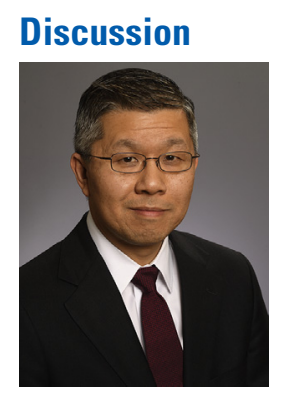

Dr E. Chen (Atlanta, Ga). I congratulate you on this outstanding study and great presentation. This project is the latest contribution from an ongoing effort spanning over 2 decades from the Yale group to help us all better understand the natural history of thoracic aortic pathology, as well as provide recommendations for treatment algorithms. Although there is increasing consensus that diameter may be one of several factors that we must consider to influence the occurrence of adverse events, it probably remains the most objective parameter we have at the present time. I would like to ask a few questions.

Certainly we are seeing in our institution more patients referred for possible repair of aortic pathology who need intervention in the setting of reoperative surgery, and I was wondering if you could enlighten us on how this algorithm would change for someone, say, needing an ascending root and arch who has already had previous cardiac or aortic surgery instead of redo surgery.

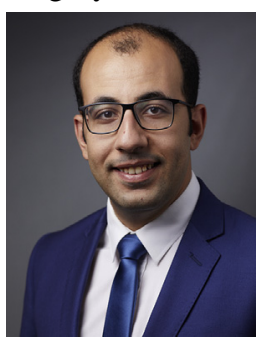

Dr Saeyeldin (New Haven, Conn). We would be a little more tolerant of the aortic diameter if the patient had a previous cardiac surgery because of the slightly increased risk, but it would not be a major factor affecting the decision. We tend to operate routinely on patients with prior cardiac surgeries, such as an aortic valve replacement or a coronary artery bypass graft, and on other high-risk patients.

Dr Chen. Your group has also previously published on the use of ASI as a decision-making tool to determine intervention versus medical observation. Could you tell us how that might have played into the treatment algorithm here.

Dr Saeyeldin. We have indeed published on the ASI and more recently on the AHI, by indexing the aortic diameter to the patient's height; however, we do not use that nomogram often, except in the extremes of body sizes, the extremely large patients or smaller patients. Having said that, in our article we performed the statistical analysis using the height index and size index. Patients in the higherrisk groups according to the nomograms were more likely 
to develop aortic events. The receiver operating characteristic curves also yielded high area under the curve with these indices. Therefore, these calculations were consistent with our previous observations.

Dr Chen. In the setting of chronic dissection of the proximal aorta, whether residual dissection after a previous repair or the diagnosis of a de novo chronic dissection previously undiagnosed, how would the presence of that disease process play into your decision making?

Dr Saeyeldin. For the purpose of uniformity, we included only patients without dissection for this algorithm. However, chronic type A AD in the patients with ascending aneurysm is rare. It can lead to a lot of scarring and increase the risk of rupture, but it is usually managed in the same way with the same diameter criteria.

Unidentified Speaker. Excellent presentation, a lot of the information that you always learn from Dr Elefteriades' group. I have 1 question and an observation that there were significant adverse events in patients who had chronic kidney disease. In our practice, I have seen a few patients who presented with type I dissection; they also had adult polycystic kidney disease. Perhaps I have a hypothesis, but probably it's not proven, that there might be a correlation of an APKD gene mutation with some aortopathy, which is probably not known. Was there any subset of population in whom you observed a significant amount of younger patients with APKD disease?

Dr Saeyeldin. Of our patients, 1 patient had polycystic kidney disease. We tend to do whole exome sequencing in our patients, and the list of genes associated with aortic aneurysms continues to grow. However, we do not exactly know an exact correlation with polycystic kidney disease and aortic aneurysms at this time.

Unidentified Speaker. I think perhaps there can be a review in which people who are at higher risk, especially with this mutation or polycystic kidney disease, can be considered for follow-up if they have any large aorta, especially at the higher risk for dissection and other complications.

Dr Saeyeldin. This is a great point, and we will definitely look into that. 